\title{
Integrating Artificial Agent in the Simulation Model of the Russian Federation Spatial Development
}

\author{
Aleksandra Mashkova \\ Orel State University \\ named after I.S. Turgenev \\ Orel, Russia \\ CEMI RAS \\ Moscow, Russia \\ aleks.savina@gmail.com
}

\author{
Olga Savina \\ Orel State University \\ named after I.S. Turgenev \\ Orel, Russia \\ Belgorod State University \\ Belgorod, Russia \\ o.a.savina@gmail.com
}

\author{
Mamatov A.V. \\ Belgorod State University \\ Belgorod, Russia \\ mamatovav@bsu.edu.ru
}

\begin{abstract}
In this paper we present a model of spatial development of the Russian Federation and principles of integrating artificial agents into it. The model is agent-based and consists of several modules, representing demographic, economic, financial processes, employment and consumption, educational and administrative institutions. Acting subjects in the model are artificial agents presenting population of the Russian Federation, who are capable of individual decision making, interaction with each other and the environment. Social activity of the agents depends on their current living standard and level of discontent. To reproduce behavior of artificial agents we implement architecture Plan-Image, based on the cognitive model, proposed by D. Miller, J. Galenter and K. Pribram. Dynamics of the model of the Russian Federation spatial development is determined by behavior of agents within educational, employment and migration processes.
\end{abstract}

Index Terms - agent-based model, artificial agent, cognitive architecture, spatial development, education, migration, employment.

\section{INTRODUCTION}

In this paper we present structure of an agent-based computer model of the Russian Federation spatial development, which reflects age and sex structure and resettlement of population, composition of households, regional economic structures, administrative and educational institutions. We have chosen agent-based modeling as a main method in this study, since it allows to reflect dynamics of a macro-system as a result of the interaction of micro-level objects. The concept of agent-based modeling was proposed in the 1990s [1] and since then has been widely disseminated in the analysis of economic, financial, social and environmental processes [2-5].

An important direction of agent-based modeling is integration of knowledge about human cognitive processes, methods of their formalization and computer implementation with social structures, reflecting decision-making environment [6-10]. However, direct use of artificial agents' architectures in agent-based models is difficult due to several reasons. First, artificial agents' architectures are focused on solving technical problems, rather than reproducing social behavior [11-14]. Secondly, use of complex multi-level architectures limits the number of active agents in simulation models [15-16].

Environment in the model of the Russian Federation spatial development is complex and diverse, so agents need a special architecture to interact with it. To reproduce behavior of agents as acting subjects of socio-economic processes we implement cognitive architecture Plan-Image. The architecture got its name according to TOTE cognitive model, proposed by D. Miller, J. Galenter and K. Pribram [17]. TOTE model describes the cycle of achieving a goal in interaction with the environment, thus architecture based on it reproduces social behavior of the agents taking into account their bounded rationality. We determine behavior of agents within educational, employment and migration processes, since these spheres significantly affect dynamics of the spatial development.

\section{STRUCTURE OF THE SIMULATION MODEL OF THE RUSSIAN FEDERATION SPATIAL DEVELOPMENT}

The developed model includes a number of interconnected modules: Demographics, Education, Employment, Production \& Service, Consumption \& Saving, Finance and Administration (see Fig. 2). Each module corresponds to the spatial structure of the Russian Federation, which means that each region has its own population, production and educational system corresponding to other regions and state administration.

State administration determines structure of the budget, taxation scale, transfer payments, the interest rate and other parameters. Regional administrations implement their functions through educational, medical, social security and defense budgetary organizations.

The module "Demography" reflects maturation, birth and death of agents in each region. New households are formed after marriages and divorces. 


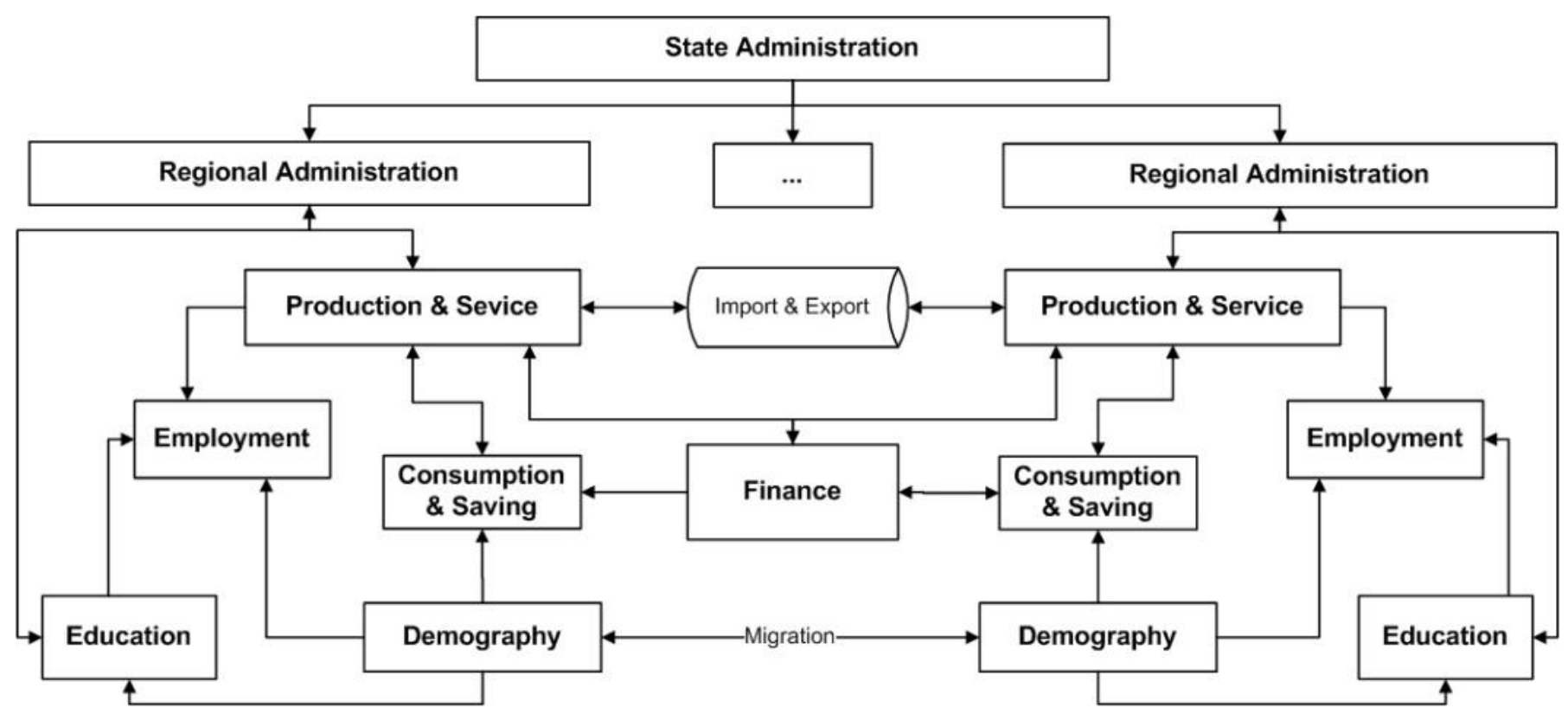

Fig. 1. Interrelation between modules of simulation model of the Russian Federation spatial development.

Population is connected with the economy through employment on the one hand, and consumption on the other. The main decisions each agent is capable of are: choice of level and specialty of their education, type and sector of employment and region of residence. The consumer in the model is not an individual agent, but a household. Members of a household have common budget and property; they share their incomes (wages, profits, pensions and other transfers). Income, expenditure and property of households is accounted, which makes it possible to assess financial state of a household during a simulation (e.g. when a household applies for a credit) and calculate statistics on structure of income and consumption of households after the simulation.

Acting subjects of the model, along with individual agents and households, are organizations. The model includes three types of organizations: commercial, financial and budgetary. Each type of organization has its own accounting system, which is a simplified version of the system adopted in the Russian Federation. Economic transactions and mutual settlements of organizations are reflected in their accounting; financial results for a year are calculated in a balance sheet; for commercial organizations, a profit and loss statement is also constructed. Workplaces are linked with organizations; each agents-employee is assigned to a workplace [18].

Educational system turns students into qualified graduates. This function is realized through the recruitment of students, transferring them to the following courses and assigning them a specialty at the end of the educational institution (module "Education"). Graduates are assigned to the employment center, which selects vacant jobs, corresponding to their qualifications (module "Employment").

Financial system in the model includes the Central Bank and regional financial organizations that accept deposits and credit organizations and households (module "Finance").
We collect statistics in the model using accounting methods. Modeling results after a simulation include the gross national and regional product, structure of import and export, dynamics of regional human resources and standards of living of the population. The model of the Russian Federation spatial development is realized as a computer program. We enter arrays of initial modeling data on the input interface; the output interface presents modeling results in the form of statistical tables, maps and graphs.

\section{PARAMETERS OF SOCIAL ACTIVITY OF AN ARTIFICIAL AGENT}

Interaction of agents with the model environment is determined in education, employment and migration processes. In the educational sphere agents choose level of professional education (secondary or higher) and specialty. After graduating agent chooses to be an employee or a businessman and sector of economy for his future job. Agents can change region of their residence. The migration aspect is directly related to education if agent is an entrant, or with employment, if he is a graduate or a qualified employee.

Behavior of agents in the model is based on the principle of bounded rationality, which means that agents search for satisfactory, not necessarily optimal solutions. Deviation of solutions from the optimum is due to cognitive limitations of agents: incompleteness of information about the external world, limited analytical and computational capacities. Thus, processes of decision making and problem solving of bounded rational agent would differ from the standard principle of utility maximizing by using alternative mechanisms for searching and evaluating solutions: copying and inertia.

The process of copying is connected with assimilation and reproduction of samples; it is a key concept of dynamic psychology. Particular attention is paid to the copying 
mechanism in the context of transactional analysis, where human behavior is seen as conditioned by a scenario - a program formed in childhood under the influence of samples [19].

Inertia is the consent to the default option. This phenomenon is studied in the behavioral economy [20]. Depending on the inertia parameter, agents gravitate toward changes in various degrees.

In the model, agents are grouped into activity clusters that integrate inertia and copying mechanisms. Concept of the clusters is based on the grouping proposed by Rogers in diffusion of innovation model. Table 1 shows average percentage of agents in each cluster according to Rogers' estimates [21], as well as strategies of their behavior in the model.

TABLE I. CLUSTERS OF SOCIAL ACTIVITY IN THE MODEL

\begin{tabular}{|c|c|c|c|}
\hline Cluster & $\begin{array}{c}\text { Average } \\
\text { percentage }\end{array}$ & Strategy of behavior & Inertia \\
\hline Innovators & 2,5 & Problem solving & $0,1 . .0,3$ \\
\hline $\begin{array}{l}\text { Early } \\
\text { adopters }\end{array}$ & 13,5 & $\begin{array}{l}\text { Copying of the strategy of } \\
\text { the most successful agents } \\
\text { in the society }\end{array}$ & $0,3 . .0,5$ \\
\hline $\begin{array}{l}\text { Early } \\
\text { majority }\end{array}$ & 34 & $\begin{array}{c}\text { Copying of the strategy of } \\
\text { the most successful } \\
\text { acquaintances }\end{array}$ & $0,5 . .0,7$ \\
\hline $\begin{array}{l}\text { Late } \\
\text { majority }\end{array}$ & 34 & $\begin{array}{l}\text { Copying of the strategy of } \\
\text { the closest acquaintances }\end{array}$ & $0,7 . .0,8$ \\
\hline Laggards & 16 & $\begin{array}{l}\text { Copying of the strategy of } \\
\text { the majority }\end{array}$ & $0,8 . .1$ \\
\hline
\end{tabular}

Innovators in the model use in-depth analysis when they make decisions; their behavior is ruled by utility maximization principle; their rationality is limited only by availability of information. Agents of other clusters are less initiative and use copying mechanisms. Inertia of the agents is set by a threshold level of discontent (TD); when an agent reaches this level, he becomes active and initiative.

Activity of an agent depends on degree of satisfaction with his social position. We use a fuzzy function for evaluation, which allows to reflect its subjectivity, caused by differences in the individual characteristics of agents, personal experience and influence of the environment. Fuzzy estimate of the living standard (ELS) is given in the form of a piecewise linear function with two parameters: a subsistence level $(S L)$ and an acceptable income $(A I)$ :

$$
\begin{gathered}
E L S(x)=\left\{\begin{array}{l}
w \cdot\left(\frac{x-S L}{A I-S L}\right), x<A I \\
1, x \geq A I
\end{array}\right. \\
w=\left\{\begin{array}{l}
0, x<S L \\
1, S L \leq x \leq A I
\end{array}\right.
\end{gathered}
$$

where $x$-income of the agent, $w$ - normalizing coefficient, $S L$ - subsistence level, $A I$ - acceptable income.

Agent's living standard is in the critical zone if his income (per member of the household) is less than the subsistence level. In the segment from the subsistence minimum to an acceptable income, the value of the ELS function is between 0 and 1, which reflects agent's satisfaction with his living standard. Income higher than $A I$ corresponds to a subjectively high living standard.

Parameters $S L$ and $A I$ are individual for each agent. $S L$ is determined by price level in the region of residence and agent's group of spending. $A I$ depends on the standard with which the agent compares himself. Choice of the standard is determined by the agent's activity cluster. For example, agents from cluster Early majority compare their income with the most successful acquaintances; Later majority and Laggards compare their income with the average income in the region.

Depending on their cluster and available information agents set the estimate of expected living standard (EELS). If the difference between EELS and ELS is positive, the agent accumulates dissatisfaction $(A D)$, which after reaching a threshold value $(T D)$ allows him to overcome inertia. $A D$ depends on the scale between ELS and EELS and time $(t)$, during which the agent was dissatisfied (Figure 2).

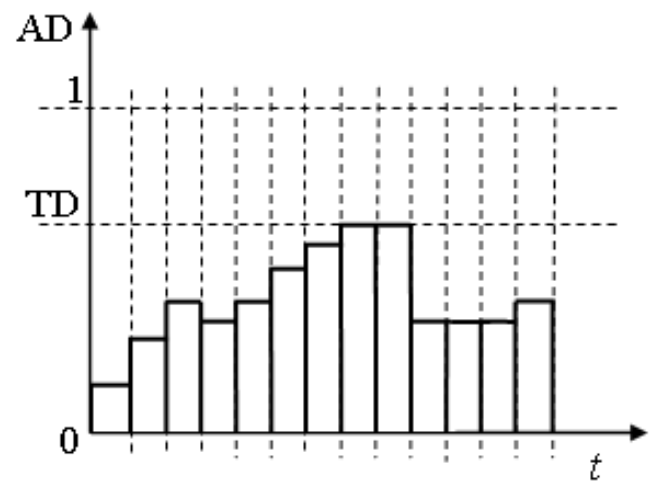

Fig. 2. Dynamics of accumulated dissatisfaction

Value of threshold level of discontent $T D$ is individual for each agent and is determined by its cluster.

\section{COGNITIVE ARCHITECTURE OF AN ARTIFICIAL AGENT}

Behavior of agents in the social environment of the model of the Russian Federation spatial development is determined by their cognitive architecture. Implemented in our research TOTE architecture is based on the cognitive model, proposed by Miller, Galanter and Pribram. TOTE (Test-Operate-TestExit) describes the cycle of goal achievement in interaction with the environment. Basic concepts in TOTE model are Plan and Image. Plan is a set of actions that an agent can make; Image consists of information that is available to him. [16]

Image of each agent includes objective and subjective information (Figure 3). Objective parameters reflect social status of the agent: his gender, age, level of education, employment and income. Subjective parameters of Image include current estimate of the living standard ELS, level of accumulated dissatisfaction $A D$, and personal records of three types:

Plan - future events aimed at achieving agent's social goals; is represented by dyad <Date, Event $\rangle$;

History - key events that occurred with an agent in the past; is represented by dyad <Date, Event $>$; 
Alternatives - possible solutions and estimates of living standard after their implementation; is represented by dyad $<$ Event, EELS $>$.

\begin{tabular}{|l|l|}
\cline { 2 - 2 } \multicolumn{2}{|c|}{ Image of the agent } \\
\hline Objectives & Subjectives \\
Age & ELS \\
Sex & Dissatisfaction \\
Education & Plan \\
Region of residence & History \\
Income & Alternatives \\
\hline
\end{tabular}

Fig. 3. Components of Image of the agent

Image changes during information exchange between agents. Plan changes through implementation of a decisionmaking algorithm that includes calculating estimates of living standard, communication and actualization of Alternatives (Figure 4). If there are active tasks in Plan, agent continues to operate according to Plan, until he completes the current task (Operate phase). When the task is completed, information about it is transferred from Plan to History (Exit phase). If Plan is empty, then the agent estimates his current living standard (1), updates the list of alternatives via public and personal information channels, and actualizes estimate of each alternative. When the agent compares his current state with the expected one, he takes as a basis the best alternative, which he is aware of. Then the agent updates the level of discontent. If current estimate of the living standard exceeds the maximum expected estimate of the living standard, the agent keeps his current position (Exit phase), otherwise achievement of the threshold level of discontent is checked. If the $T D$ is crossed, the agent adds new task to Plan, which would implement the best alternative, and moves to Operate phase. Actions in Operate phase are determined by the environment.

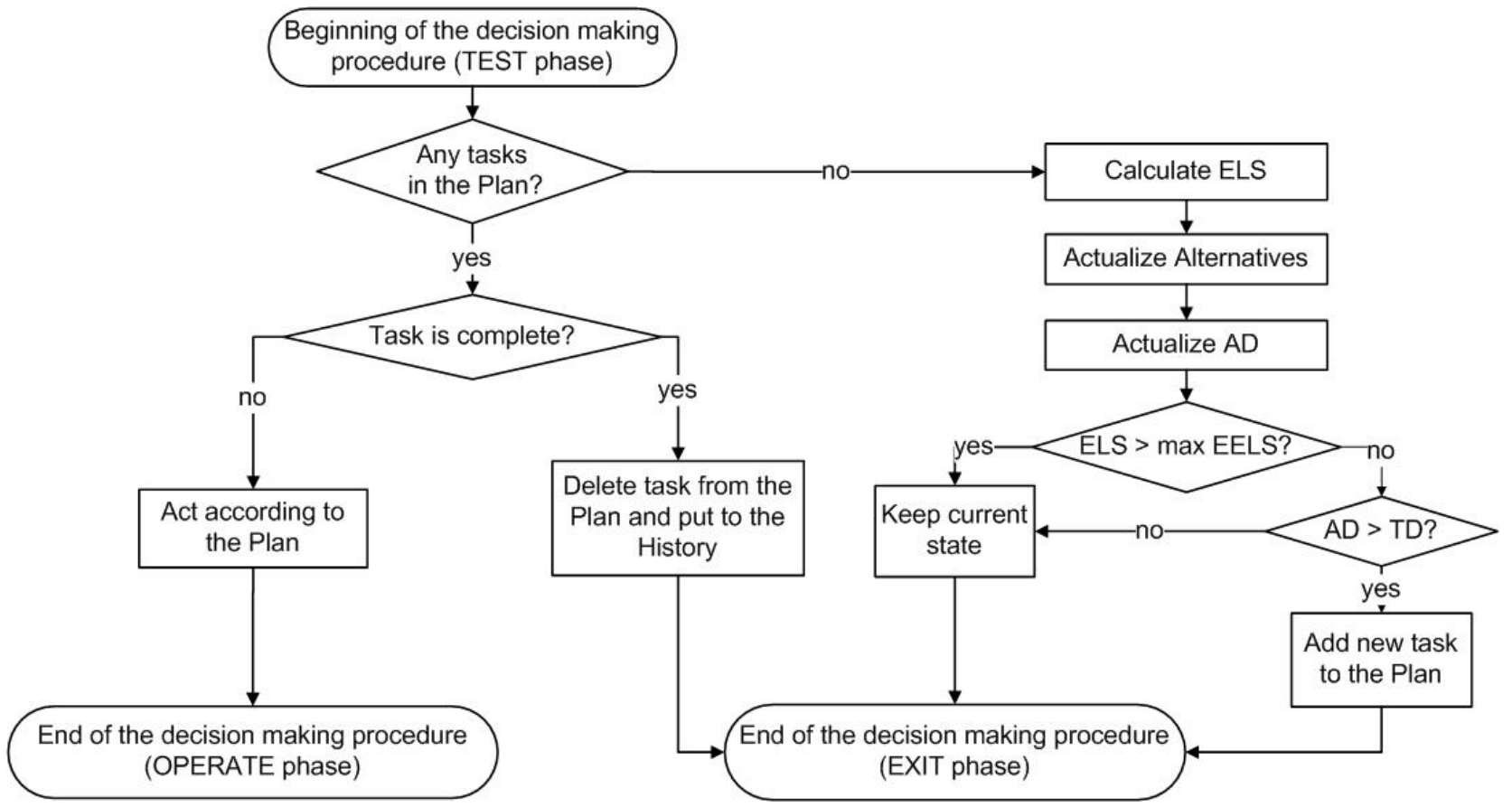

Fig. 4. Algorithm of realization of Plan

\section{BEHAVIOR OF AGENTS IN THE SOCIAL ENVIRONMENT}

If there are active tasks in Plan, the agent acts to complete them. Actions are implemented to education (admission / graduation), employment or migration.

Educational system in the model consists of regional educational organizations with which educational places are connected. Agents with an active task "Admission to the educational organization" submit applications; educational organizations conduct competitive contest. After the contest successful agents are assigned to educational places; they add task "Graduate from the educational organization" to their Plan and record <"Admission", Date> to their History. Each year agents-students are promoted to the next course. After graduation agents are assigned with a qualification; they remove task "Graduate from the educational organization" from their Plan and add record <"Graduation", Date > to their History (Figure 5). 


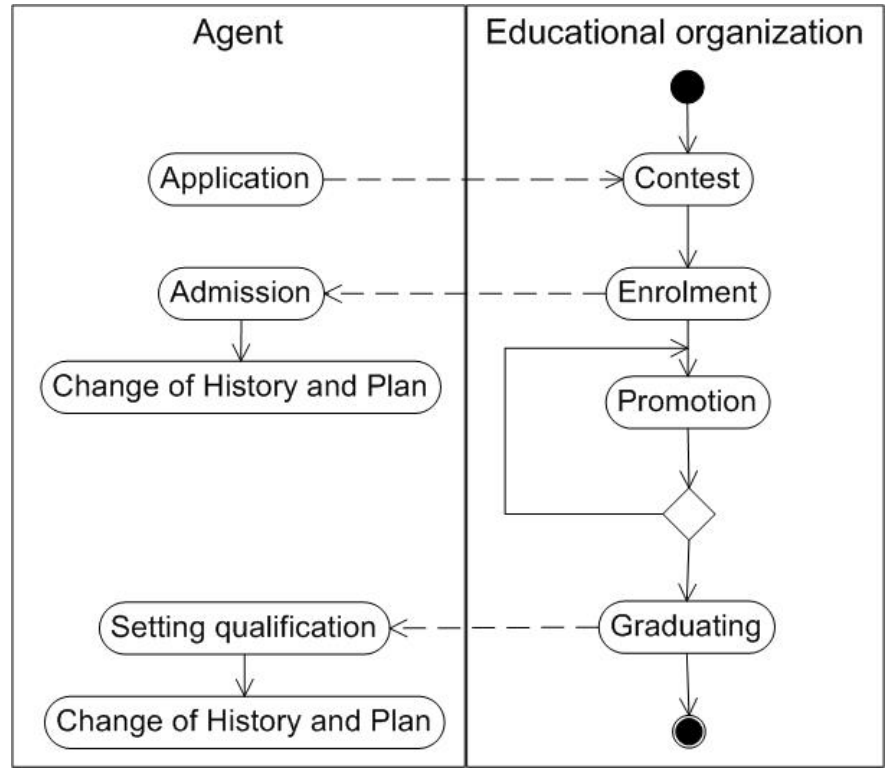

Fig. 5. Interactions between an agent and an educational organization

Graduates of educational organizations and persons who lost their jobs due to reduction, dismissal, relocation or other reasons are assigned to the regional employment center. The center receives information on vacancies from regional organizations and conduct employment contest. The aim of the contest is to find agents with the required qualification and assign them to workplaces (Figure 6). After the employment agents remove task "Employment" from their Plan and add record <"Employment; Organization", Date> to their History.

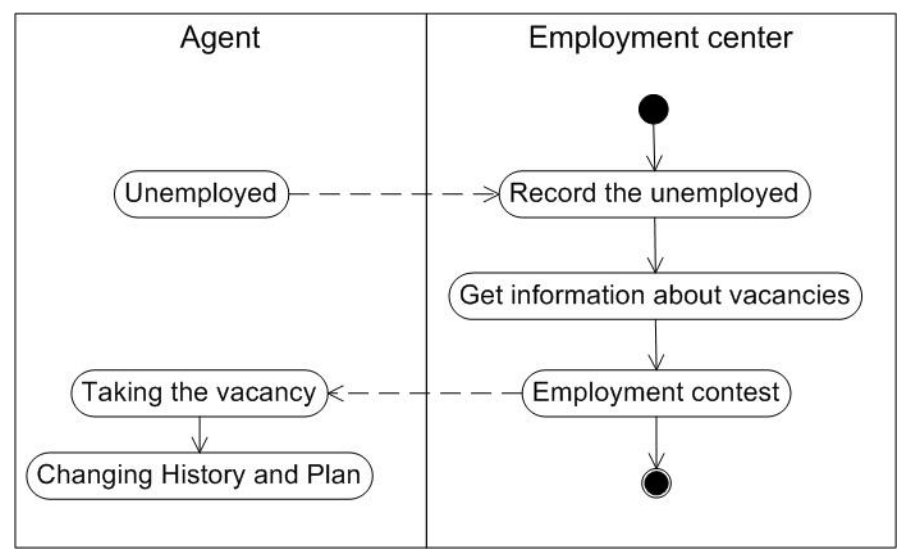

Fig. 6. Interactions between an agent and an employment center

When the agent decides to change the region of residence, he fires from the workplace or expulses from the educational organization and vacates his apartment, if there are no other tenants. After this, the agent moves to the selected region, where he rents an apartment, assigns to the educational organization or the employment center. The task "Migration" is removed from Plan; record <"Migration, Region", Date> is added to History

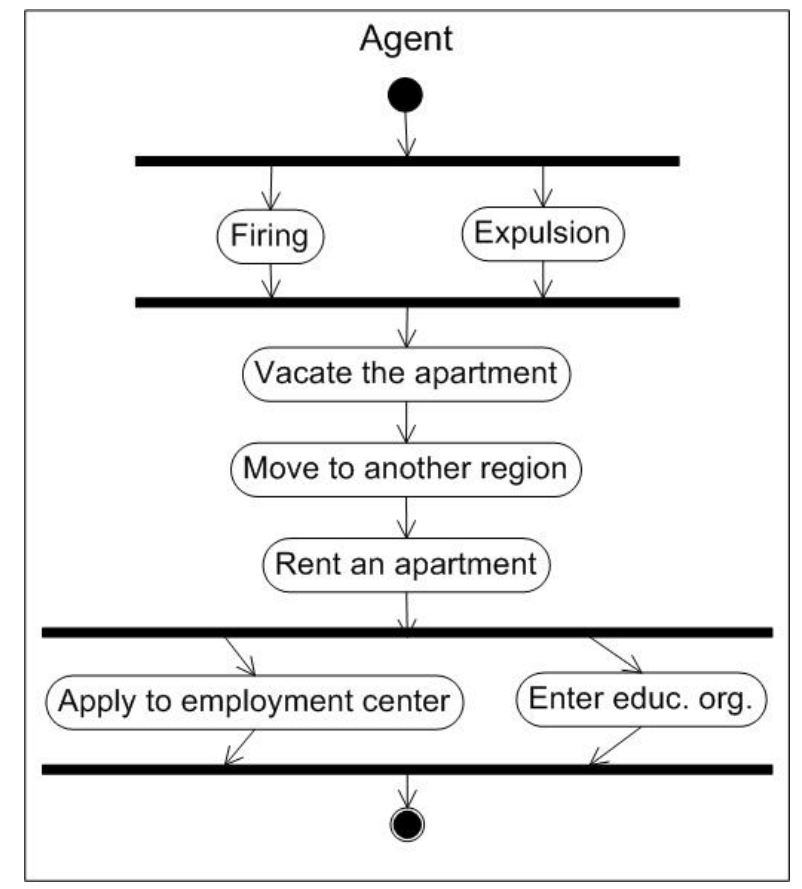

Fig. 7. Migration of an agent to a different region

Individual decisions of agents in the spheres of education, employment and migration determine social dynamics of the model, in particular, quantitative and qualitative characteristics of regional human resources. Composition of human resources affects productive capacities of the regional economy; development of the economy, in turn, influences on human resources dynamics through changing living standards of the population.

\section{CONCLUSION}

In the presented research methodology we integrate artificial agent into the simulation model of the Russian Federation spatial development, which would allow to predict social dynamics as a result of individual decisions.

After program realization and loading initial data sets, the model would provide assessments of managerial decisions consequences and their influence on the economic system in a spatial context, taking into account existing production capacities, infrastructure and human resources of the regions.

The proposed approach can be applied to a wide range of studies at the level of separate regions and the Russian Federation as a whole. The modular structure of the model allows, on the one hand, to detail considered processes and institutions, and on the other - to expand the range of studied phenomena, including social stability in the Russian Federation, involvement of population in political processes and long-term economic dynamics connected with structural and technological changes. An important direction is also further development of decision-making procedures of artificial agents that present population of the Russian Federation in the model by increasing their ability to analyze information and take into account irrational aspects of behavior. 
The reported study was funded by RFBR according to the research project № 18-29-03049.

\section{REFERENCES}

[1] J. Epstein, R. Axtell, Growing Artificial Societies: Social Science From the Bottom Up, MIT Press, Brookings Institution, 1996.

[2] A.L. Mashkova, O. A. Savina, S.A. Lazarev, "Agent Model for Evaluating Efficiency of Socially Oriented Federal Programs," in: Proceedings of the 11th IEEE International conference on application of Information and Communication Technologies, vol.2. Moscow: V. A. Trapeznikov Institute of Control Sciences of Russian Academy of Sciences, 2017, pp. 217-221.

[3] L. Tesfatsion, "Agent-based computational economics: Growing economies from the bottom up," Artificial Life vol.8, pp.55-82, 2002.

[4] J.M. Epstein, "Modeling civil violence: an agent-based computational approach,” in: Proc. Natl. Acad. Sci. USA, vol. 99, pp.7243-7250, 2002.

[5] F.F. Feitosa, Q.B Le, P.L.G Vlek, "Multi-agent simulator for urban segregation (MASUS): A tool to explore alternatives for promoting inclusive cities," Computers, Environment and Urban Systems, vol.35 (2), pp.104-115, 2011

[6] R. Sun, "Prolegomena to Integrating Cognitive Modeling and Social Simulation," in: Cognition and Multi-Agent Interaction From Cognitive Modeling to Social Simulation, Cambridge: Cambridge University Press, pp. 3-28, 2006.

[7] M. Niazi, A. Hussain, "Agent-based computing from multi-agent systems to agent-based models: A visual survey," Scientometrics, vol.89, pp. 479-499, 2011.

[8] M.P. Wellman, "Putting the agent in agent-based modeling," Autonomous Agents and Multi-Agent Systems, November 2016, vol.30(6), pp.1175-1189, 2016.
[9] N. Gilbert, "When Does Social Simulation Need Cognitive Models?" in: Cognition and Multi-Agent Interaction From Cognitive Modeling to Social Simulation. Cambridge University Press, pp. 428-432, 2006.

[10] J.H. Holland, J.H. Miller, "Artificial Adaptive Agents in Economic Theory," AEA Papers and Proceedings, vol.5, pp. 365-370, 1991.

[11] J. Anderson, The architecture of cognition, Cambridge, MA: Harvard University Press, 1983.

[12] N. Taatgen, C. Lebiere, J. Anderson, "Modeling Paradigms in ACT-R," in: Cognition and Multi-Agent Interaction from Cognitive Modeling to Social Simulation, Cambridge: Cambridge University Press. pp. 29-52, 2006.

[13] A. Newell, Unified theories of cognition, Cambridge, MA: Harvard University Press, 1990.

[14] R. Sun, "The CLARION Cognitive Architecture: Extending Cognitive Modeling to Social Simulation," in: Cognition and Multi-Agent Interaction from Cognitive Modeling to Social Simulation, Cambridge University Press, pp. 79-102, 2006.

[15] P. Caillou, B. Gaudou, A. Grignard, C.Q. Truong, P. Taillandier, “A Simple to-use BDI architecture for Agent-based Modeling and Simulation," in: The Eleventh Conference of the European Social Simulation Association (ESSA 2015), Sep 2015, Groningen, Netherlands, 2015.

[16] R. Sun, I. Naveh, "Social institution, cognition, and survival: a cognitive-social simulation," Mind and Society, vol.6, pp.115-142, 2007

[17] G.A. Miller, E. Galanter, K.H. Pribram, Plans and the structure of behavior, New York: Henry Holt, 1960.

[18] A.L. Mashkova, A.V. Demidov, O. A. Savina, A.V. Koskin, E.A. Mashkov, "Developing a Complex Model of Experimental Economy Based on Agent Approach and Open Government Data in Distributed Information-Computational Environment," in: Proceedings of International Conference Electronic governance and open society: challenges in Eurasia 2017, New York, USA: ACM, 2017, pp. 27-31.

[19] E. Berne, What do you say after you say hello? The psychology of human destiny, New York: Bantam Books, 1973.

[20] R.H. Thaler, C. R. Sunstein, Nudge: Improving Decisions About Health, Wealth, and Happiness, updated edition. New York: Penguin, 2009.

[21] E.M. Rogers, Diffusion of innovations, 5th ed. New York, NY: Free Press, 2003 